\title{
Recepción de léxico de confitería decimonónico en diccionarios del español
}

\section{Reception of the Lexicon of Nineteenth-Century Confectionery in Spanish Dictionaries}

Marta Torres Martínez [matorma@ujaen.es]

Universidad de Jaén, España

\begin{abstract}
RESUMEN
En la presente investigación nos aproximamos a un tratado culinario publicado a mitad del siglo XIX,Elconfitero moderno (1851) de José Maillet. Nuestro objetivo se centra en estudiar el vocabulario incluido al final de la obra y, en concreto, analizar las voces de especialidad compiladas en él. En primer lugar, disponemos onomasiológicamente estas palabras para después revisar su presencia, tratamiento y evolución en la tradición lexicográfica del español — tanto académica como extraacadémica-. Nos centramos en determinar si los ítems léxicos objeto de estudio se registran en los diccionarios generales del español y, en tal caso, en qué época se lematizan y cómo se incorporan en la macro y microestructura de los distintos repertorios. En definitiva, este trabajo permitirá arrojar luz sobre una de las parcelas del léxico decimonónico de la vida social, a saber, la culinaria y, más específicamente, la relativa al ámbito de la confitería.
\end{abstract}

\section{Palabras Clave}

léxico histórico; confitería; lexicografía española; siglo XIX

\begin{abstract}
The present research approaches José Maillet's The Modern Confectioner (1851), a culinary treaty published in the middle of the 19th century. Our central objective is to study the vocabulary included at the end of the aforementioned work and, in particular, to analyse the specialty terms compiled in it. Firstly, we arrange these words in onomasiological order to later revise their presence, treatment and evolution in the academic and extra-academic tradition of the Spanish lexicography. We focus in determining whether the lexical items under study are registered in the general dictionaries of the Spanish language and, in such a case, in which period they are lemmatised and how they are incorporated in the macro and microstructure of the different catalogues. In short, this paper will shed light on one of the areas of the nineteenth-century lexicon concerning social life, namely, the culinary one and, specifically, the one related to the field of confectionery.
\end{abstract}

\section{KEYWORDS}

historical lexicon; confectionery; Spanish lexicography; 19th century

RECIBIDO 2016-09-30; ACEPTADO 2016-12-30 


\section{Introducción}

El confitero moderno. Tratado completo y práctico de confitería y de pastelería, del licorista y de toda clase de refrescos pertenecientes a la repostería, con el método de preparar toda clase de encurtidos, firmado por José Maillet, fue impreso en Barcelona en 1851, aunque Martínez Llopis (1995: 377) en su Historia de la gastronomía española lo fecha en 1859 y, además, indica que el apellido del autor es Maitlet.

En la página web de la Real Academia de Gastronomía encontramos una ficha de esta obra en la que se describe como "un recetario especializado en pastelería y confitería, aunque incluye recetas variadas de bebidas, encurtidos, etc." También se señala que "en la parte final, se ofrece un vocabulario con términos comunes empleados en el ámbito gastronómico”. Del autor no se dan detalles, solo se alude a la información contenida en el prólogo, donde se indica que José Maillet “posee muchísimos años de práctica en los principales establecimientos de Francia y España”.

Esta obra se compone de cuatro partes. En la primera se aborda el "conocimiento de los principales productos"; en la segunda, se ubica un "tratado completo y práctico de pastelería"; la tercera parte se titula "Del licorista destilador" y, finalmente, la cuarta trata "De la repostería".

El breve prólogo consta de cuatro párrafos en los que el autor, en primer lugar, destaca lo completa y asequible que es la obra, de singular índole en España ("Hasta ahora no había en España un tratado tan completo de confitería y al alcance de todas las personas como el presente"). Seguidamente, Maillet defiende la simplicidad del Tratado, lograda gracias a su hábil traducción ("La mayor parte de los publicados contienen preceptos de difícil ejecución y muchísimas veces irrealizables, pues que siendo generalmente traducidos por personas estrañas al arte no han sabido interpretar la idea del autor”). En el tercer párrafo, Maillet detalla su dilatada experiencia en el oficio, según se ha visto más arriba, así como el objetivo que persigue ("explicar todos sus preceptos con tanta claridad y sencillez que hasta a las personas que no tengan ningún conocimiento les sea fácil de ejecutar cuanto prescribe en su obra"). Finalmente, el autor convence al lector, tanto al experto en confitería como al mero aficionado a la cocina, de la gran utilidad de su obra, pues "es de suma e indispensable necesidad a los confiteros, pasteleros, licoristas, reposteros y cocineros, y muy útil en fin a todas las personas amigas de confeccionar por sí mismas toda clase de confituras, pastas, fiambres y encurtidos".

Cabe destacar uno de los aspectos señalados por Maillet en el prólogo, a saber, el hecho de que esta obra supone una traducción, entendemos que de otra de carácter similar, gestada en una lengua diferente al español. Aunque ni en los preliminares ni en el cuerpo del Tratado se cita obra alguna, pronto relacionamos este texto con otro de origen francés titulado Le confiseur moderne ou l'art du confiseur te du distillateur (1803), de J. J. Machet e impreso en París.

No obstante, la estructura del tratado francés difiere de la que posee la obra de Maillet, pues Le confiseur moderne consta de cinco partes centradas en (i) el conocimiento de las sustancias simples, (ii) el azúcar y el chocolate, (iii) las confituras, (iv) la destilación y (v) productos diversos de perfumería. En cambio, nos percatamos de que ambos tratados tienen en común sus últimas páginas, donde se sitúan sendos vocabularios objeto de nuestro interés en esta investigación. 


\section{El Vocabulario de El confitero moderno (1851) de José Maillet}

En efecto, el tratado de Maillet se cierra con un breve vocabulario, al que no se alude en las palabras introductorias del autor, compuesto de 78 ítems:

(1) ablandar, alambique, alisar, almirez, amasar, aplanar, arenar, aventar, baño de azúcar, bañomaría, baño de arena, barquilleros, batidor, batir, blanquear, brasero de hierro, brillantar, cacerole o cazuela, cacito de pico, cajones, caldera de balancín, caldero, candidera, capitel, cazo con mango, cedazo, cestilla, colar, confitar, criba, cucurucho, cucurbita, decantar, decocción, desecar, destilar, dorar, embudo con mango, empringar, enharinar, escobilla, escurridera, espátula, esprimir, espumadera, estufa, evaporar, filtrar, filtradora, horno, hornillo o hornilla, infusión, jeringa, levadura de cerveza, macerar, majar, manga, manga para bizcochos, matraz, moldes, mondar, mosto, perol, pétalos, pistilo, planchas, recipiente, rectificar, rodillo, sable de madera, sacabocado, secar o cubrir, serpertín, sorbetera, tamiz, tonel, tostar, triturar.

También hallamos en Le confiseur moderne un vocabulario al final de la obra ("Vocabulaire des termes techniques pour l'intelligence de ce traité”), tal como reconoce Machet en su prólogo: “Enfin, je termine l'ouvrage par un court Vocabulaire qui explique certains termes techniques qu' il est indispensable d'employer si on veut éviter les circonlocutions" (Machet 1803: XI).

El vocabulario de la obra francesa incluye 147 lemas y, si bien hay algunos que coinciden con los que integran el repertorio de Maillet (confire/confitar,bain-marie/baño-maría,blanchir/blanquear, décanter/decantar, décoction/decocción o infusion/infusión), la mayoría de los ítems difieren ${ }^{1}$.

Si nos centramos en el corpus léxico de (2), observamos que, desde el punto de vista gramatical, se documentan dos tipos de categorías: verbo (27) y sustantivo (51). En cuanto a su morfología, no todas las unidades léxicas son monoverbales, pues encontramos 11 voces pluriverbales (baño de azúcar, baño-maría, baño de arena, brasero de hierro, cacito de pico, caldera de balancín, cazo con mango, embudo con mango, levadura de cerveza, manga para bizcochos, sable de madera). Entre las monoverbales, se hallan 4 voces creadas con sufijos diminutivos (cacito, cestilla, escobilla y hornillo u hornilla).

Desde el punto de vista semántico, constatamos que las voces listadas se relacionan con los ámbitos de la confitería, pastelería y destilería, centros de interés de El confitero moderno. En este sentido, si organizamos los ítems onomasiológicamente, encontramos cuatro categorías:

1 A continuación, listamos las 147 entradas del "Vocabulaire" de Machet: abaisser, acerbe, acides, alexitère, alcali, alcohol, analyse, anti-septique, anti-spasmodique, apéritif, assortissoir, astringens, bain-marie, baie, béchique, blanchet, blanchir, blanchir, calice, candir, candis, cannelon, carminatif, carrelet, cassons, caustique, céphalique, chancir, charger, chausse, clarequet, clarification, clayon, coffret, cohober, colature, concasser, concret, confire, cordial, cornue, cosmétiques, crème-vierge, décanter, décoction, décuire le sucre, dégraisser, dentrifice, diablotins, diaphorétique, digérer, diurétique, drastique, egouttoir, elixir, embryon, empyreume, étamine, evaporation, exotique, exprimer, extraire, fèces ou lie, fécule, fers, filtrer, flegme, fouet, four de campagne, galons, garder au liquide, gaufrier, gimblette, glacer, glaces, grainer, grillage, hépatique, hétérogène, histèrique, homogène, houlette, hydragogue, impalpable, imprégné, incisif, incrassant, indigène, infusion, lait virginal, laxatif, lénitif, liquéfier, lut, macérer, matras, monder, moule, mousseline, mousses, mout, mucilage, neige, nervoir, nompareille, ombellifère, onctueux, onglet, orangeat, oxycrat, oxymel, parenchyme, pate, perloir, pistil, raréfié, récipient, rectifier, ressuer le chocolat, sachets, sédimens, sophistication, sorbetière, spatule, suc, sudorifique, tailladins, tambour, tamis a glace, terrasse, tirer au sec, torréfier, tour, tourner, tournures, travailler une glace, triturer, tube ou tuyau, vaisseaux de rencontre, vapeurs, vermifuge, videlle, volatil, vulnéraire, zester, zestes. 
(2) Acciones: ablandar, alisar, amasar, aplanar, arenar, aventar, batir, blanquear, brillantar, colar, confitar, decantar, desecar, destilar, dorar, empringar, enharinar, esprimir, evaporar, filtrar, macerar, majar, mondar, rectificar, secar o cubrir, tostar, triturar.

Ingredientes: levadura de cerveza, mosto, pétalos, pistilo.

Instrumentos: alambique, almirez, barquilleros, batidor, brasero de hierro, cacerole o cazuela, cacito de pico, cajones, caldera del balancín, caldero, candidera, capitel, cazo con mango, cedazo, cestilla, criba, cucurucho, cucurbita, embudo con mango, escobilla, escurridera, espátula, espumadera, estufa, filtradora, horno, hornillo o hornilla, jeringa, manga, manga para bizcochos, matraz, moldes, perol, planchas, recipiente, rodillo, sable de madera, sacabocado, serpentín, sorbetera, tamiz, tonel.

Procesos: baño de azúcar, baño-maría, baño de arena, decocción, infusión.

A continuación, por motivos de espacio, nos centramos en los ítems adscritos exclusivamente al campo de la confitería, atendiendo a la definición asignada en el vocabulario de Maillet. Nos interesa, en concreto, el significado de especialidad de las voces en cuestión a fin de comprobar si se recoge en los diccionarios del español detallados más adelante. Por tanto, analizamos el siguiente corpus:

(3) ablandar, alisar, arenar, aventar, baño de azúcar, barquilleros, blanquear, brillantar, cacito de pico, cajones, candidera, cestilla, confitar, cucurucho, dorar, escobilla, manga para bizcochos, perol, rodillo, sable de madera, secar o cubrir, sorbetera, tonel.

Al final del trabajo se incorpora un anexo en el que se compilan estas voces objeto de estudio. En concreto se ofrece una descripción microestructural para cada ítem, compuesta de (i) entrada, (ii) definición documentada en El confitero moderno (1851) de Maillet y, en su caso, (iii) primera documentación lexicográfica en los diccionarios consultados. 


\section{Revisión lexicográfica de las voces relativas a la confitería}

Nos ocupamos, seguidamente, de revisar la presencia, tratamiento y evolución de las voces listadas en (3), tanto en la lexicografía académica como en la extraacadémica. Para ello empleamos las herramientas que la Real Academia Española pone en su página web al servicio del público, aprovechadas fundamentalmente por los investigadores en el ámbito de la filología, en general, y de la lexicología y lexicografía, en particular. Manejamos, de un lado, el Diccionario de autoridades (1726-39) y el Mapa de diccionarios ${ }^{2}(M d D)$ a la hora de examinar los repertorios académicos y, de otro lado, consultamos el Nuevo tesoro lexicográfico de la lengua española ${ }^{3}$ (NTLLE) para analizar los diccionarios adscritos a la corriente extraacadémica. Además, observamos si las palabras de nuestro corpus se incluyen en el Tesoro de la lengua castellana o española (1611) de Sebastián de Covarrubias ${ }^{4}$. Comprobamos, además, la pervivencia de las voces en la lexicografía española actual, mediante la consulta de la última edición del DRAE (2014) y de un diccionario descriptivo gestado a finales del siglo XX, el Diccionario del español actual (DEA, 1999), de Manuel Seco, Olimpia Andrés y Gabino Ramos.

2 "El Mapa de diccionarios es una herramienta que permite, en la actualidad, consultar simultáneamente seis ediciones representativas del diccionario académico: 1780, 1817, 1884, 1925, 1992 y 2001. Su finalidad radica en ofrecer una visión evolutiva del léxico moderno, matizada por la idea que se hacían de él los académicos a lo largo de los casi trescientos años en que se suceden las ediciones de estos diccionarios" (Fundación Rafael Lapesa 2012b: en línea).

3 "El Nuevo tesoro lexicográfico de la lengua española (NTLLE) reúne una amplia selección de las obras que durante los últimos quinientos años han recogido, definido y consolidado el patrimonio léxico de nuestro idioma [...] El NTLLE es un diccionario de diccionarios, un diccionario que contiene todo el léxico de la lengua española desde el siglo XV hasta el XX, tal y como es recogido, sistematizado, definido e inventariado por los más importantes repertorios lexicográficos” (Real Academia Española: en línea).

$4 \quad$ El Tesoro de la lengua castellana o española (1611) de Sebastián de Covarrubias, pionero en la lexicografía española monolingüe, se alza como el único precedente hispánico con que cuenta la Academia para la elaboración del Diccionario de autoridades (1726-39). El repertorio de Covarrubias ha sido objeto de estudio de numerosos lingüistas, tales como Lépinette (1989), Azorín (2000), García-Macho (2002) y Seco (2003a[1987], 2003b [1987] y 2003c[1987]), entre otros. Estos trabajos se centran especialmente en analizar los aspectos formales del Tesoro. Por ejemplo, Azorín (2000: 25) advierte de su disposición anárquica y poco sistemática, debido al desorden ortográfico, la ausencia de un criterio fijo a la hora de seleccionar las voces o las continuas ingerencias personales de Covarrubias en la redacción de los artículos; mientras que García-Macho (2002: 2089) y Seco (2003a[1987]: 193-94) se centran en caracterizar algunas cuestiones concernientes a su macroestructura -inclusión de nombres propios (topónimos, antropónimos, hidrónimos, etc.), repetición de entradas o falta de criterio en la agrupación de familias léxicas contenidas en los artículos- y microestructura — variedad en las definiciones, esfuerzo etimológico o inclusión de textos informativos de carácter doctrinal o literarios - Por otra parte, Seco (2003b [1987] y 2003c[1987]) estudia las autoridades literarias documentadas en el Tesoro y el influjo de este repertorio en el primer diccionario académico, respectivamente.

5 Tal como señala Alvar Ezquerra (2002: 390), es relevante la publicación del Diccionario del español actual porque es un repertorio construido a partir de una nueva planta que parte de "datos directamente comprobados". Se trata de un diccionario descriptivo, no normativo, en el que se emplea un lenguaje moderno a la hora de redactar las definiciones, así como un criterio actual al ordenar las distintas acepciones de los lemas recogidos. Según advertía Seco (1997: 138) antes de la publicación del $D E A$, este diccionario sincrónico se basa en tres pilares fundamentales: (i) “la orientación descriptiva", (ii) "la definición de una sincronía precisa para la descripción del léxico contemporáneo"y (iii) "la creación de un corpus documental como fundamento indispensable para el establecimiento del léxico objeto de la descripción”. En concreto, en relación con esta última característica, Alvar Ezquerra (2002:390) declara que el DEA es "una obra que ha venido a romper con la inercia en que se movían nuestros diccionarios monolingües desde el Diccionario de autoridades, o, por decirlo con la precisión necesaria, desde que la Academia prescindió de las autoridades literarias para sacar rápidamente el diccionario en un volumen, de 1780". No obstante, el autor recuerda más adelante la excepción que supone Aniceto de Pagés, autor que incluye citas en su repertorio, como apuntamos más adelante. 
Nos interesa, primeramente, señalar las voces de nuestro corpus que no quedan registradas en la tradición lexicográfica: ablandar ${ }^{6}$, alisar, arenar, aventar ${ }^{7}$, brillantar $^{8}$, cacito de pico ${ }^{9}$, cajones ${ }^{10}$, candidera, cestilla, sable de madera, secar o cubrir y tonel.

En segundo lugar, las que se registran en los diccionarios de nuestra lengua, podemos distribuirlas en 6 grupos:

(i) El significado de especialidad, adscrito al ámbito de la pastelería, se documenta desde los orígenes de la lexicografía monolingüe, aunque no se mantiene a lo largo de los siglos ni tampoco se conserva en nuestros días. Tal es el caso de perol:

(4) PEROL, un género de vaso de metal abierto, que se pone sobre el fuego y se adereçan en él todos los géneros de conservas que se hazen en açúcar y miel; y por averse para estar sobre el fuego, se dijo perol, quasi pirol (Tesoro, 1611: s. v.).

PEROL. s. m. Vaso de metal mui abierto de boca, y en figura de una media esphera, que sirve para cocer diferentes cosas, y particularmente para aderezar y componer todo género de conservas, que se hacen con azúcar o miel [...] (Diccionario de autoridades, 1726-39, s. v.).

Es interesante la evolución de la acepción tanto en los diccionarios académicos como en los no académicos, pues de lo concreto deriva a lo general en el ámbito de la culinaria. Por ejemplo, en el $M d D$ observamos que, mientras que los repertorios de los siglos XVIII y XIX siguen a Covarrubias y especifican que un perol servía "para aderezar y componer todo género de conservas que se hacen con azúcar o miel” (DRAE 1780, 1817 y 1884) ${ }^{11}$, los publicados ya en el siglo XX

6 Castro y Rossi en su Biblioteca universal. Gran diccionario de la lengua (1852) recoge un significado aproximado al consignado por Maillet, si bien no alude al posterior confite de los alimentos ('Tratándose de carnes y de frutas, es perder la entereza, ponerse en estado de ser comidas con más facilidad, gusto y provecho' s. v. ablandarse).

7 No obstante, Castro y Rossi (1852) y, posteriormente, Gaspar y Roig en el Diccionario enciclopédico de la lengua española (1853-55) incluyen una acepción localizada en Cuba y relativa al café ('Cuba. Limpiar el café sirviéndose del aventador'). También Alemany, ya en el siglo XX, en Diccionario de la lengua española (1917) alude a este significado ('Amér. En Cuba, limpiar el café de su cáscara por medio del aventador').

8 A partir del DRAE (2001) hallamos dos acepciones relativas a la confitería, marcadas dialectalmente, no bajo el lema brillantar, sino contenidas en el artículo lexicográfico de abrillantar ('Arg., Ur. y Ven. confitar (| cubrir con un baño de azúcar)' y ‘Cuba. Cubrir un producto de pastelería con clara batida’).

9 Esta voz pluriverbal no se registra en ningún diccionario del corpus. No obstante, cabe destacar que, bajo el lema cacito, Zerolo en su Diccionario enciclopédico de la lengua castellana (1895) recoge la siguiente acepción: 'Amér. Cuba. Vasija de metal a manera de chocolatera y anafe. También se dice perol y pailón'. También encontramos este significado, aunque menos preciso, en el Diccionario de la lengua española (1917) de Alemany Bolufer ('Amér. En Cuba, especie de jarro de metal, más alto que ancho, con mango') y en el Diccionario general y técnico hispano-americano (1918) de Rodríguez-Navas ('Amér. En Cuba, vasija de metal en forma de anafe'). No en vano, en el Fichero general de la RAE, encontramos una cédula en la que se muestra el artículo de cacito en el Diccionario provincial de voces cubanas (1875[1836]) de Pichardo, inspirador de nuestros lexicográfos ("cacito. s. m. Nombrase así en la parte occidental la vasija pequeña especie de jarro de metal más alta que ancha con su mango a modo de la chocolatera de España. En la parte central se denomina perol y en la oriental pailón”).

10 Cabe destacar que en el DRAE (1925) se incluye la acepción 'casilla o garita de madera que sirve de tienda o de obrador', que se mantiene hasta la última edición del diccionario académico. En los repertorios lexicográficos no académicos se reconoce su empleo como tienda, pero no como obrador.

11 A finales del siglo XIX en un repertorio de especialidad como el Diccionario general de cocina (1892) de Ángel Muro perol queda aún caracterizado como 'Utensilio de metal en figura de media esfera, que sirve para cocer diferentes cosas, y particularmente para aderezar y componer todo género de conservas que se hacen con azúcar o miel. Generalmente es de cobre amarillo’. 
lo caracterizan como un instrumento usado "para cocer diferentes cosas" (DRAE 1925, 1992, 2001 y 2014).

(ii) El significado relacionado con la confitería se registra desde los primeros repertorios, perdura a lo largo de la tradición lexicográfica y aún se mantiene en nuestros días. En este grupo encontramos baño y confitar:

(5) BAÑO. Se llama también el que se da a los dulces y bizcochos con azúcar, y el que se da a la cera, a la losa, y otras cosas con otros ingredientes [...] (Diccionario de autoridades, 1726-39, s. v.).

CONFITAR. v. a. Cubrir o bañar con azúcar alguna fruta, semilla u otra cosa semejante (Diccionario de autoridades, 1726-39, s. v.).

En el caso de baño, el Diccionario de autoridades no sublematiza la unidad pluriverbal baño de azúcar, sino que en la propia definición alude al ingrediente que recubre los dulces y bizcochos. A lo largo de los siglos, esta acepción se incluye tanto en diccionarios académicos como no académicos — que siguen como modelo la definición del primer diccionario académico-, si bien destacamos la definición que presenta Biblioteca universal. Gran diccionario de la lengua (1852) de Castro y Rossi, coincidente con la de El confitero moderno ('Capa de dulce en los confites'). Llama la atención, en cuanto a la tradición académica, que el $D R A E$ (2014) presente una definición similar a la consignada a finales del siglo XIX, en el DRAE (1884): 'Capa de materia extraña con que queda cubierta la cosa bañada; p. ej., la de azúcar en los dulces, la de cera en varios objetos o la de plata u oro en cubiertos y alhajas'.

En cuanto a confitar, también se recoge ya en el Diccionario de autoridades y esta definición sigue incluyéndose, tanto en los repertorios académicos como los no académicos, sin apenas variación. Cabe destacar el caso de Terreros, en cuyo Diccionario castellano (1786-93[1767]) se documenta una definición detallada, de clara índole enciclopédica ('Dar a las flores, frutas, hierba, raíces, etc. cierta preparación, que las hace más agradables, e impide en mucha parte la corrupción [...] Antiguamente solo se hacía con miel, ahora se usa mucho del azúcar'). Además, advertimos que Rodríguez-Navas (1918) asigna la marca Art. y Of. al significado que nos atañe ('Cubrir con baño de azúcar, frutas o semillas, preparadas al efecto'). Esta voz, al ser productiva y de carácter general, se repertoriza en diccionarios de nuestros días como el Diccionario del español actual (1999) de Seco, Andrés y Ramos ('Recubrir con un baño de azúcar [frutas o frutos secos]') o la última edición del DRAE ('Cubrir con un baño de azúcar una fruta o una semilla para hacerla más agradable al paladar'12).

(iii) La acepción concerniente al ámbito de la confitería no se recoge desde los inicios, pero se incorpora a finales del siglo XVIII, se documenta en los diccionarios del corpus y se le sigue dando cabida en la actualidad. Encontramos aquí voces como barquilleros, dorar o cucurucho.

Barquilleros se define en el Diccionario de autoridades como 'el que hace o vende barquillos de massa' y es a partir del DRAE (1780) cuando se empieza a registrar la acepción de 'molde de hierro

12 Hemos observado que, además de este significado, en el $M d D$ se incorporan otros dos relacionados con la cocina: 'Cocer las frutas en almíbar' (marcado como aragonesismo solo en 1780 y 1817) y 'Endulzar, suavizar'. Estas acepciones también se documentan en todos los repertorios extraacadémicos incluidos en el NTLLE. 
para hacer barquillos', tanto en la tradición académica como en la extraacadémica hasta la actualidad. Destacamos de nuevo a Castro y Rossi (1852) como innovador a la hora de caracterizar esta palabra ('Molde de hierro para fabricar barquillos y hostias'). Además, al igual que en el caso de confitar, Rodríguez-Navas (1918) marca esta voz con la etiqueta Art. y Of.

En lo que respecta a dorar, Terreros (1786-93[1767]) incluye la acepción de especialidad 'En las pastelerías, echar yema de huevo por encima a alguna pieza, pastel, etc.', recuperada en los siglos XIX y XX por Gaspar y Roig (1853-55) y Rodríguez-Navas (1918), 'En las pastelerías, echar yema de huevo por encima a alguna pieza, pastel, etc.' y En Pastelería, echar yema o azafrán a una cosa para hacerla amarillear', respectivamente. La Academia no incorpora este significado en sus diccionarios, sino que registra, a partir de 1925, otro relativo a la cocina pero no tan específico ('Tostar ligeramente una cosa de comer'), al igual que ocurre en el repertorio de Seco, Andrés y Ramos (1999): 'Asar o freír [algo] hasta que tome color dorado'13.

Cucurucho aparece definido desde el DRAE (1780) como 'Papel arrollado en forma de cono. Sirve para poner dinero, dulces, ú otras cosas: los penitentes y trompeteros los usan de carton muy grandes para capirotes en semana santa'. Esta definición se documenta en todos los diccionarios de nuestro corpus. Cabe destacar el repertorio de Seco, Andrés y Ramos (1999), que incluye dos significados relativos a la culinaria: 'Papel o cartulina enrollados en forma cónica que sirve esp. para llevar dulces u otros alimentos menudos' y 'Barquillo cónico sobre el que se sirve una bola de helado. Tb el conjunto'.

(iv) El significado técnico que nos ocupa se registra a partir del siglo XIX y se mantiene en nuestros días. Así, únicamente en el Diccionario nacional o Gran diccionario clásico de la lengua española (1853[1846-47]) de Ramón Joaquín Domínguez se da cabida, bajo rodillo, a la subentrada rodillo de chocolatería ('con el que se muele el cacao'). Más tarde solo se incorpora en las tres últimas ediciones del DRAE (1992, 2001 y 2014) como 'Cilindro de madera para estirar la masa'14.

A veces observamos pérdida de carga semántica. Tal es el caso de blanquear, que a lo largo de los siglos XVIII y XIX solo es definido por Gaspar y Roig (1853-55) como 'Entre confiteros, limpiar bien las frutas y quitar cierta pelusilla que tienen, metiéndolas en una lejía preparada al efecto' $\mathrm{y}$, en consecuencia, marcado diatécnicamente (Art. $y$ Of.). Ya a partir del siglo XX lo encontramos recogido en las últimas ediciones académicas ('Hervir durante unos minutos un alimento para que pierda su acidez o la sangre' en 1992;'Escaldar un alimento durante unos minutos, para ablandarlo, quitarle color, etc.' en 2001 y 2014). Curiosamente, Seco, Andrés y Ramos (1999) asignan la marca Coc. a la acepción 'Hervir brevemente en agua [un alimento] para que se reblandezca, o para que se ponga blanco o no se oscurezca', que no se corresponde con la documentada en Maillet ('Operación que se hace en los confites después de engrosados').

13 En el Pequeño diccionario ilustrado de los términos usuales en la cocina (1900) de José de Praussols se incorporan dos acepciones más relacionadas con el ámbito de la confitería: 'Cubrir con lo que se llama caramelo la superficie de cualquier vianda' y 'Dar color a las salsas con caramelo'.

14 En el Diccionario general de cocina (1892) de Muro rodillo se define de una forma precisa como el 'cilindro manuable de madera, de media vara de largo y dos o tres pulgadas de diámetro, que sirve para golpear, sentar, batir y extender las masas y pastas en las operaciones de pastelería, dulcería y en algunas de cocina'. 
(v) La acepción adscrita al ámbito de la confitería se documenta únicamente en un par de diccionarios de los corpus, anteriores al siglo XX. Encontramos tal circunstancia en el caso de escobilla, caracterizada solo por Terreros (1786-93[1767]) como 'Entre pasteleros, hisopillo para dar con hiema de huevo a los pasteles o piezas que doran'. Gaspar y Roig (1853-55) la recupera posteriormente, ya en el siglo XIX ('Especie de hisopillo de que usan los confiteros para dar con yema de huevo a los dulces o pasteles que doran').

(vi) El significado de especialidad que nos interesa se registra en diccionarios del siglo XX, tal como observamos en sorbetera y manga para bizcochos.

Sorbetera solo se documenta en los repertorios de Alemany (1917) y Rodríguez-Navas (1918), así como en el Gran diccionario de la lengua castellana autorizado con ejemplos de buenos escritores antiguos y modernos [...] (1902-1931) de Pagés y Puig: 'vasija para hacer sorbetes', 'aparato para hacer sorbetes,' 'vasija para hacer sorbetes', respectivamente. Este significado no se recoge en el MdD, pero sí en las ediciones de 1983-85 y 1989 del Diccionario manual e ilustrado de la lengua española de la $\mathrm{RAE}^{15}$. El repertorio de Seco, Andrés y Ramos (1999) incluye esta palabra y la definen como 'Utensilio destinado a la preparación de sorbetes y helados'.

En cuanto a manga para bizcochos, el significado aportado por Maillet se registra, bajo manga, en el DRAE 1992, 2001 y 2014 ('Utensilio de tela, de forma cónica, provisto de un pico de metal u otro material duro, que se utiliza para añadir nata a algunos pasteles, decorar tartas, etc.') así como en el repertorio de Seco, Andrés y Ramos (1999), que reconoce su ámbito de especialidad e incluso lo identifican bajo las unidades pluriverbales manga de pastelero o manga pastelera ('Cono de tela con boquilla, que se usa esp. en pastelería para decorar. Gralm $\sim$ de pastelero, $\mathrm{o} \sim$ pastelera' ${ }^{16}$.

15 No obstante, en el Fichero general existen 12 cédulas relativas a sorbetera. Dos de ellas incluyen sendas obras de Ángel Muro: el Diccionario general de cocina (1892) y El practicón: tratado completo de cocina al alcance de todos y aprovechamiento de sobras (1894). En el repertorio lexicográfico se define sorbetera como "el utensilio que sirve para helar y hacer los sorbetes", mientras que la cédula relativa a El practicón recoge la voz sorbetera en la receta del queso helado ("Se hiela la crema en la sorbetera, y cuando esté bien concreta se llena un molde"). El resto de casos se refieren al empleo de la voz en América, concretamente en Cuba (Los argonatutas, 1916, de Jesús Castellanos: "De la cocina, por último, llegaron hasta muy avanzado el crepúsculo tintineos de ensaladas y batidos rumores arrastrados de sorbeteras") o Nicaragua (Diccionario del habla nicaragüense, 1948, de Alfonso Valle: "Mujer que hace y vende sorbetes. Utensilio para hacer sorbetes"). Francisco J. Santamaría en su Diccionario general de americanismos (1942) reconoce una acepción general ("Lugar o traste a propósito para poner los sorbetes helados") y otra localizada en Argentina ("En Argentina, vasija que sirve para guardar sorbetes").

16 En todos los diccionarios del corpus hallamos recogido el siguiente significado: 'Cierto instrumento hecho en figura de un cucurucho, que se fabrica de estameña, lienzo, bayeta, ó papel de estraza, y sirve para colar los licores'. 


\section{Valoración final}

En este estudio hemos constatado que el significado de especialidad relacionado con el ámbito de la confitería de las voces de nuestro corpus se documenta, en algunos casos, ya desde los orígenes de la lexicografía monolingüe del español (perol desde Covarrubias o baño y confitar desde el Diccionario de autoridades), si bien la acepción técnica de algunas palabras se va incorporando a lo largo de la tradición, esto es, en el siglo XVIII (barquilleros, cucurucho, dorar, escobilla), siglo XIX (blanquear, rodillo) y siglo XX (manga, sorbetera). No obstante, debido previsiblemente a su concreta adscripción, destacamos que la mitad de los ítems analizados no encuentran acomodo en diccionarios generales de nuestra lengua, tales como alisar, candidera, cestilla, sable de madera o tonel, entre otros, palabras cuyo significado se recoge en el anexo final.

En definitiva, teniendo en cuenta "la negligencia o desinterés filológicos por la culinaria" (Gemmingen 1995: 401), esta investigación se alza como una modesta aportación a los estudios históricos del léxico especializado en este ámbito.

Sin duda, el espulgo de otros tratados culinarios o de textos relacionados con el ámbito de la alimentación y la gastronomía nos permitirá compilar un mayor volumen de léxico y, por otro tanto, esbozar ampliamente una clasificación de tipo onomasiológico ${ }^{17}$, pues somos conscientes de que, como señala Eberenz (2014: 26-27):

Desde el punto de vista histórico, la alimentación, con sus categorías y sus conceptos fundamentales, parece ocupar el centro de un área temática mucho más extensa en la que se sitúan sectores como la culinaria, en cuanto arte de elaboración de los alimentos, los utensilios de cocina, la vajilla y los cubiertos, las distintas comidas del día, los oficios y los cargos de cocina y de mesa si pensamos en la alimentación de las clases privilegiadas, bien representada, por ejemplo, en la literatura. Además, el dominio de la alimentación linda con otros que pueden ser interesantes para el estudio antropológico y lexicológico, como la agricultura y la ganadería, la economía en general, la biología y, muy especialmente, la medicina.

\section{Referencias bibliográficas}

Alvar Ezquerra, M. (2002). De antiguos y nuevos diccionarios del español. Madrid: Arco/Libros. Azorín Fernández, D. (2000). Sebastián de Covarrubias y el nacimiento de la lexicografía. In I. Ahumada (Ed.), Cinco siglos de lexicografía del español (pp. 3-34). Jaén: Universidad de Jaén.

Covarrubias Horozco, S. (2006[1611]). Tesoro de la lengua castellana o española. Edición integral e ilustrada de Ignacio Arellano y Rafael Zafra. Madrid: Universidad de Navarra/Iberoamericana/Vervuert/Real Academia Española/Centro para la Edición de Clásicos Españoles.

17 En un reciente estudio, Eberenz (2016: 82) destaca que "La organización semántica del vocabulario español de los alimentos y de su preparación culinaria es un territorio todavía poco explorado, situación que contrasta con la de la pletórica investigación realizada sobre la historia social y económica de la alimentación en la Península Ibérica. En la mayoría de los estudios lexicológicos, las palabras relativas a la comida se presentan como listados alfabéticos de nombres de platos, productos, carnes y vegetales comestibles. Solo unos pocos distinguen entre denominaciones de preparados concretos y nombres de grandes conjuntos de manjares". 
Eberenz, R. (2014). El léxico español de la alimentación y la culinaria en su historia: fuentes y líneas de investigación. In V. Álvarez Vives, E. Díez Del Corral Areta, \& N. Reynaud Oudot (Eds.), Dándole cuerda al reloj. Ampliando perspectivas en lingüística histórica de la lengua española (pp. 23-46). Valencia: Tirant humanidades.

. (2016). De lo crudo a lo cocinado: sobre el léxico fundamental de la culinaria en la historia del español (siglos XIII a XVII). Revista de Filología Española, XCVI, 81-112.

Fundación Rafael Lapesa. (2012a). Diccionario de Autoridades. <http://web.frl.es/DA.html>

$[M d D]$ : - (2012b). Mapa de diccionarios. <http://web.frl.es/NTLLEt/SrvltGUILoginNTLLEtPub> . (2012c). Fichero general. <http://web.frl.es/fichero.html>

García-Macho, Ma L. (2002). Macroestructura y microestructura en los diccionarios de Alfonso de Palencia, Antonio de Nebrija y Sebastián de Covarrubias. In Ma T. Echenique Elionza, \& J. Sánchez Méndez (Eds.), Actas del V Congreso Internacional de Historia de la Lengua Española (I) (pp. 2075-2091). Madrid: Gredos.

Gemmingen, B. (1995). Estudios lexicológicos sobre la lengua culinaria del Siglo de Oro. Revue de Linguistique Romane, 59(235-236), 402-417.

Lépinette, B. (1989). Contribution a l' étude du Tesoro de la lengua castellana o española (1611) de Covarrubias. Historiographia Linguistica, XVI(3), 257-310.

Machet, J. J. (1803). Le confiseur moderne ou l’art du confiseur te du distillateur. París: Imprenta de Guilleminet.

Maillet, J. (1851). El confitero moderno. Tratado completo y práctico de confitería y de pastelería, del licorista $y$ de toda clase de refrescos pertenecientes a la repostería, con el método de preparar toda clase de encurtidos. Barcelona: Imprenta y librería de la Sra. V. E. H. de Mayol.

Martínez Llopis, M. (1995). Historia de la gastronomía española. Huesca: La Val de Onsera/Ministerio de Agricultura, Pesca y Alimentación.

Muro, Á. (1892). Diccionario general de cocina. Madrid: Imprenta de Jose M. ${ }^{a}$ Faquineto.

Praussols, J. (1900). Pequeño diccionario ilustrado de los términos usuales en la cocina. Madrid: Imprenta de Hernando.

[NTLLE]: Real Academia Española. Nuevo tesoro lexicográfico de la lengua española. <http://ntlle.rae.es/ntlle/SrvltGUILoginNtlle>

Seco, M. (1997). El Diccionario sincrónico del español. In T. Cabré, \& M. Lorente (Eds.), Cicle de conferènces 95-96. Lèxic, corpus y diccionaris (pp. 133-149). Barcelona: Institut Universitari de Lingüística Aplicada/ Universitat Pompeu Fabra.

- (2003a [1987]). Un lexicógrafo de la generación de Cervantes (Notas sobre el Tesoro de Covarrubias). In Estudios de lexicografía española (pp. 185-201). Madrid: Gredos.

_. (2003b [1987]). Autoridades literarias en el Tesoro de Covarrubias. In Estudios de lexicografía española (pp. 202-221). Madrid: Gredos.

. (2003c [1987]). Covarrubias en la Academia. In Estudios de lexicografía española (pp. 222-236).

Madrid: Gredos.

[DEA]: Seco, M., Andrés, O., \& Ramos, G. (1999). Diccionario del español actual. Madrid: Aguilar. 


\section{Anexo: corpus de voces adscritas al ámbito de la confitería}

Ablandar: La acción que reciben los frutos cuando se cuecen con agua para confitarlos después. [No documentada]

Alisar: Última operación que se hace a los confites. [No documentada]

Arenar: Menear con una espátula el azúcar cuando ha llegado al punto volante para que forme el grano. [No documentada]

Aventar: Echar al aire con el aventador las cáscaras de cacao. [No documentada]

Baño de azúcar: Cuando se escurre el líquido de los dulces mientras se están confitando, los cuales después de calentados o bien hervido se echan encima de los frutos. [Diccionario de autoridades, 1726-39, s. v. baño]

Barquilleros: Moldes de hierro en forma de tenazas que tienen dos palas redondas en la estremidad que juntadas contienen una cucharada de pasta que sirve para hacer el barquillo; suelen ser grabados en la parte interior y para que cierren herméticamente tienen una argolla en el mango. [DRAE, 1780, s. v. barquillero]

Blanquear: Operación que se hace en los confites después de engrosados. [Gaspar y Roig, 1853-55, s. v.]

Brillantar: Los dulces que relucen en la superficie por medio de la cristalización o bien por efecto del azúcar brillante que se le pone. [No documentada]

Cacito de pico: Diminutivo del cazo con mango que sirve para hacer las pastillas a la gota. [No documentada]

Cajones: Sirven para poner los polvos de almidón donde deben imprimirse los moldes que se quieren hacer los bombones: suelen tener tres o cuatro palmos de largo por dos de ancho y una pulgada de alto. [No documentada]

Candidera: Caja de hoja de lata acompañada de un enrejado de hilo de hierro, en la que se arreglan las frutas o bombones para candir. [No documentada]

Cestilla: Sirve para poner los confites en la estufa para secar. [No documentada]

Confitar: Preparar la fruta con azúcar para que pueda conservarse. [Diccionario de autoridades, 1726-39, s. v.]

Cucurucho: Sirve para poner glasa para decorar. [DRAE, 1780, s. v.]

Dorar: Hacer tomar color en el horno a las piezas que están polvoreadas con azúcar. [Terreros, $1786-1793$ [1767], s. v.]

Escobilla: Las hay de mimbres y de hilo de hierro: sirven para montar las claras. [Terreros, 1786-1793[1767], s. v.]

Manga para bizcochos: Tiene la misma hechura que la anterior [manga 'cucurucho de bayeta que sirve para pasar los líquidos'], solo se diferencia por tener un agujero en la punta que sirve para colocar un cañoncito de hoja de lata que sirve para hacer los bizcochos; suele ser de ropa de hilo o de cualquier otra solo que sea final que no claree. [DRAE, 1992, s. v. manga]

Perol: Utensilio de cobre que sirve para hacer los turrones. [Tesoro, 1611: s. v.]

Rodillo: Palo redondo muy liso comúnmente empleado para varios artículos de pastelería; los hay también trabados al través de la superficie, estos últimos sirven en varios pastillages, etc. [Domínguez, $1853[1846-47]$, s. v.]

Sable de madera: Sirve para enarenar el azúcar cuando se ha puesto dentro de sus correspondientes formas.

[No documentada] 
Secar o cubrir: Los dulces en almíbar después de escurridos, pasados por un baño de azúcar cocido y enharinados. [No documentada]

Sorbetera: Conocida vulgarmente por el nombre de garapiñera: cubo de estaño o de hoja de lata que sirve para hacer los helados. [Alemany, 1917, s. v.]

Tonel: Especie de hornilla de madera que sirve para colocar la caldera para hacer anises u otros confites menudos. [No documentada] 
